Editorial

\title{
Climate Change and Security: Filling Remaining Gaps
}

\author{
Yasuko Kameyama $^{1, *}$ and Yukari Takamura ${ }^{2}$ \\ ${ }^{1}$ Social Systems Division, National Institute for Environmental Studies, Japan; E-Mail: ykame@nies.go.jp \\ 2 Institute for Future Initiatives, The University of Tokyo, Japan; E-Mail: yukari.takamura@ifi.u-tokyo.ac.jp \\ * Corresponding author
}

Submitted: 7 October 2021 | Published: 22 October 2021

\begin{abstract}
As perception of climate change as a threat to humanity and to ecosystems grows, the rapidly growing literature increasingly refers to the notion of "climate change and security," for which there is as yet no single agreed definition. Despite the extent of literature already published, there are at least three remaining gaps: (1) Added theoretical value: How does "climate change and security" differ from similar notions such as "climate crisis" and "climate emergency"? What theoretical gains can be made by securing against climate change? (2) Role of non-state actors: The traditional concept of security is tightly bound to the notion of national security, but the climate change and security discourse opens the door to the participation of non-state actors such as the business sector, local government, and citizens. How do they take part in ensuring security? (3) Regional imbalance: Most of the literature on climate change and security published so far comes from Europe and North America. As other regions, such as Asia, are just as affected, more voices should be heard from those regions. This issue aims to address some of these gaps. The nine articles in this issue address the notion of "climate change and security" through empirical work while theoretically contributing to several themes relating to the climate change and security discourse.
\end{abstract}

\section{Keywords}

climate change; conflict; discourse; human security; management; risk; security

\section{Issue}

This editorial is part of the issue "Climate Change and Security" edited by Yasuko Kameyama (National Institute for Environmental Studies, Japan) and Yukari Takamura (University of Tokyo, Japan).

(C) 2021 by the authors; licensee Cogitatio (Lisbon, Portugal). This editorial is licensed under a Creative Commons Attribution 4.0 International License (CC BY).

\section{Introduction}

As scientific understanding of climate change has gained wide acceptance, and as most people around the globe perceive it as a threat to humanity and to ecosystems, the rapidly growing literature on this subject increasingly refers to the concept of "climate change and security." However, there is no single agreed definition of this concept. Despite the extent of literature already published (Busby, 2019; Kameyama \& Ono, 2021; McDonald, 2013), gaps remain.

First, what is the value added by using the term "climate change and security"? How does it differ from similar expressions such as "climate crisis," "climate emergency," "mitigation," "adaptation," and "disaster management"? From a theoretical viewpoint, securing against climate change-securitization-does not sit well with traditional notions of security. The traditional study of security is tightly attached to national security and national defence, although its scope can also be broadened (Buzan, 1983). What can we gain by securitization against climate change from the theoretical perspective?

Second, do non-state actors have a role? Broadening of security notions within the "climate change and security" discourse opens the door to roles for non-state actors such as the business sector, local government, and citizens. No matter how "climate change and security" is defined theoretically, all members of society need to take part in addressing climate change. Use of the 
"climate change and security" notion could be an effective way to ensure the involvement of non-state actors in the climate change debate.

Third, there is a regional imbalance. Most of the literature published to date on climate change and security has been written by authors in Europe and North America and focuses mostly on cases in Africa, the Middle East, and the Americas. Although other regions, such as Asia, are also severely affected by climate change, experts from there are under-represented, and few case studies from there have been reported. Security is closely linked to countries' geopolitical and cultural contexts, so what constitutes "climate change and security" may differ from one region to another.

This thematic issue aims to address some of these gaps by inviting studies related to climate change and security from various parts of the world and accepting a wide scope of the notion of security. The nine articles in this issue address the issue of "climate change and security" through empirical work with theoretical contributions to several relevant themes.

\section{Themes and Articles}

\subsection{Relationship Between Climate Change and Security}

How "climate change and security" differs from other notions that are used to enhance a sense of urgency continues to be debated. How can securing against climate change be effective in arming the world against adverse impacts of climate change?

Some studies concentrate on the inter-relationship between "climate change" and "security" rather than the joint concept. Within this area of study, "security" takes the conventional definition, such as conflict and involuntary displacement.

Hardt (2021) and Jakobsson (2021) each analysed a case of organisations under the United Nations. Hardt investigated a statement jointly proposed by 10 member states of the United Nations Security Council in 2020 and asked whether the United Nations Security Council can effect transformative change in the face of the increasing recognition of climate change as a threat to security. Jakobsson investigated why climate-induced population migration took "a major agenda leap" at a specific point in time within the United Nations policy agenda. Their conclusions suggest that climate change is now widely acknowledged to be a major threat to humanity, to society, and to nation states.

Ministries of defence in many developed countries report increased dispatch of military teams to developing countries for humanitarian assistance in response to the increasing frequency of natural disasters, placing a burden on their defence sectors. Prabhakar et al. (2021) focused on the relationship between climate change and external emergency assistance to increase resilience in developing countries and to develop a new decision support system to determine the level of disaster risks, and concluded that it is important to share risk information among regional partners and to implement a mechanism to mitigate risks.

\subsection{Role of Non-State Actors}

As each individual faces risks posed by climate change, the notion of "climate change and security" must deal with securitization not only at the national level, but also at the local and community levels. Ide et al. (2021) concluded that gender roles and unequal gender structures are important context factors that shape climate-conflict risks in various regions, and that through intersection with other inequality structures, gender inequality can aggravate or change the impact of both climate change and conflict.

Two studies in this thematic issue (Koppenborg \& Hanssen, 2021; Yamada, 2021) investigate how Japanese government ministries and the business sector express climate change in their respective use of terms. They found that security-related terms are used only by those who support mitigation policies, and that lack of use of such terms could explain why Japan has not been enthusiastic in reducing greenhouse gas emissions.

\subsection{Regional Interpretation}

We are delighted to receive contributions from some countries such as Finland and Japan that have been somewhat minority in the field of climate change and security studies. All of these articles from underrepresented regions will enhance the development of climate change and security.

Three articles focused on Japan (Hasui \& Komatsu, 2021; Koppenborg \& Hanssen, 2021; Yamada, 2021). Their approaches are different, but they arrive at similar conclusions. The notion of climate change and security is not familiar in Japan. Policy makers, politicians, and the business sector all see climate change merely as an environmental problem, or energy- and economyrelated problem. The increasing extreme weather events in recent years in Japan could be a stimulus for Japanese stakeholders to see climate change as a security issue and to become more supportive of emission reduction.

Two studies (Hasui \& Komatsu, 2021; Räisänen et al., 2021) took up "comprehensive security" as another notion that could merge all types of threats, including various risks to individuals, and concluded that it could be an effective way to respond to cross-sectoral problems such as climate change.

The concept of nature-based solutions (NbS) supports the sustainable management of ecosystems in Europe, which can be seen as a way to respond to climate change from a security perspective. Morita and Matsumoto (2021) compared the implementation of $\mathrm{NbS}$ across Asia and concluded that Asian countries have developed $\mathrm{NbS}$ in their own contexts and already include it in their national strategies or plans. 
These studies suggest that, at least from the implementation point of view, usage of "climate change and security" can be diverse and interpretation can differ from one country to another, incorporating the security aspect of climate change in each country's unique context.

\section{Research Questions for Future Research}

This thematic issue was challenging in the way that it aimed at making progress in debates related to "climate change and security" from the three aspects described above. We were successful in filling some gaps, but remaining gaps still exist.

First, many studies focus on the causal relationship between climate change and conflict, but we argue, as Prabhakar et al. (2021) touch on, that development of collaborative relationships-between countries and between people-should be recognized as the best and only way to prevent conflicts and to protect ourselves from various types of damage due to climate change. No matter how "climate change and security" is defined theoretically, the notion ought to be fully utilized as a means to promote collaboration, not conflict. This is somewhat related to the role of non-state actors. Non-state actors are important because they are the ones who must change their behaviour to reduce greenhouse gas emissions and who will be affected by climate change. Issues of equity and justice and disparities within society and between societies should be further investigated to accelerate mitigation and adaptation by non-state actors.

We did our best to invite submissions from other parts of the world, particularly from major greenhouse gas emitting countries such as China, India, and Russia, without success. Those countries are all influential in terms of traditional security agenda, such as military and defence, and are sensitive about use of the term "security." Their involvement in discourse on climate change and security is indispensable to a common understanding that climate change is a security issue. They have suffered much climate-related damage. Seeing that damage from a security perspective should be important not only for those countries, but also for the whole world, if we are to prevent the worst-case scenario.

\section{Acknowledgments}

The authors would like to sincerely thank the journal staff for their kind support in compiling this issue. The issue has been made possible partially as part of a research grant JPMEERF20212002 of the Environment Research and Technology Development Fund of the Environmental Restoration and Conservation Agency (ERCA) of Japan.

\section{Conflict of Interests}

The authors declare no conflict of interests.

\section{References}

Busby, J. (2019). The field of climate and security: A scan of the literature. Social Science Research Council. https://www.ssrc.org/publications/view/the-fieldof-climate-and-security-a-scan-of-the-literature

Buzan, B. (1983). People, states \& fear: An agenda for international security studies in the post-cold war era. Pearson Education.

Hardt, J. N. (2021). The United Nations Security Council at the forefront of (climate) change? Confusion, stalemate, ignorance. Politics and Governance, 9(4), 5-15.

Hasui, S., \& Komatsu, H. (2021). Climate security and policy options in Japan. Politics and Governance, 9(4), 79-90.

Ide, T., Ensor, M. O., Le Masson, V., \& Kozak, S. (2021). Gender in the climate-conflict nexus: "Forgotten" variables, alternative securities, and hidden power dimensions. Politics and Governance, 9(4), 43-52.

Jakobsson, E. (2021). How climate-induced migration entered the UN policy agenda in 2007-2010: A multiple streams assessment. Politics and Governance, 9(4), 16-26.

Kameyama, Y., \& Ono, K. (2021). The development of climate security discourse in Japan. Sustainability Science, 16, 271-281. https://doi.org/10.1007/s11625020-00863-1

Koppenborg, F., \& Hanssen, U. (2021). Japan's climate change discourse: Toward climate securitisation? Politics and Governance, 9(4), 53-64.

McDonald, M. (2013). Discourses of climate security. Political Geography, 33, 42-51. https://doi.org/ 10.1016/j.polgeo.2013.01.002

Morita, K., \& Matsumoto, K. (2021). Governance challenges for implementing nature-based solutions in the Asian region. Politics and Governance, 9(4), 102-113.

Prabhakar, S. V. R. K., Tamura, K., Okano, N., \& Ikeda, M. (2021). Strengthening external emergency assistance for managing extreme events, systemic, and transboundary risks in Asia. Politics and Governance, 9(4), 27-42.

Räisänen, H., Hakala, E., Eronen, J. T., Hukkinen, J. I., \& Virtanen, M. J. (2021). Comprehensive security: The opportunities and challenges of incorporating environmental threats in security policy. Politics and Governance, 9(4), 91-101.

Yamada, T. (2021). Transforming the dynamics of climate politics in Japan: Business' response to securitization. Politics and Governance, 9(4), 65-78. 


\section{About the Authors}

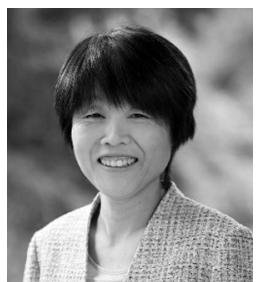

Yasuko Kameyama is the director of the Social Systems Division of the National Institute for Environmental Studies, in Japan. Her focus is on international negotiation processes concerning climate change, from an international relations perspective. Her research interests include international institution development on environmental problems, sustainable development, as well as equity-related. 